\title{
A Comparative Analysis of Effects of Education on Sub-Saharan Africa's Economic Growth
}

\author{
Akinola Gbenga Wilfred, Gerry Koye Bokana \\ College of Law and Management Studies, University of KwaZulu-Natal, Westville, Durban, South Africa \\ 214585066@stu.ukzn.ac.za, bokanakg@ukzn.ac.za
}

\begin{abstract}
This study aims to analyze and to compare the effects of various levels of education on the economic growth of some selected countries in Sub-Saharan Africa (SSA) between 1980 and 2015.It is hypothesized in the study that various levels of education have significant positive impacts on the economic growth of some selected sub-Saharan Africa countries over the stated period. Fixed effect Least Square Dummy Variable (LSDV) and a robust version of System Generalized Methods of Moment (SYSGMM) are adopted as model estimating techniques. Results from the LSDV model indicate increasing positive impacts of various levels of education on the economic growth of the thirty selected SSA countries. This trend of significance is corrected in the dynamic model, but with negative effects on the lower levels of education on growth while higher education output which negatively impacted on growth is reversed. The study systematically compares the effects of education on growth when higher education is included and when it is excluded both at the enrolment and output level in the regression model. We found different results at each instance for the various levels. Therefore, the major conclusion of this study is that higher education human capital at the output level appears to be the most significant of all the levels of education. However, this advantage enjoyed by higher education could have been as a result of cumulative effects from other levels of education over time. We, therefore, conclude that higher education should be supported with strong education policy implementation, as this could have a positive impact on SSA economic growth.
\end{abstract}

Keywords: Education, Higher Education, Economic Growth, System GMM

\section{Introduction}

Between 1980 and 2000, Sub Saharan African (SSA) countries witnessed low economic growth and low higher education enrolment (Glewwe, Maiga, \& Zhend, 2014). Sub-Saharan Africa (22 million sq. Km) is a large region in term of land coverage in the African continent. Comparatively, it is relatively wider than that of China 9.3 (million sq. $\mathrm{Km}$ ), India (2.97 sq. $\mathrm{Km}$ ) and the United States (9.1 sq. Km) altogether. Also, it is five times bigger than the twenty-eight nations in the European Union. It is well above 930 million in its population figure, and also by this population estimates; it is two times as large as the European Union. There are 46 countries in the region (World Fact book, 2017). Logically, this SSA profile potentially should place SSA region at a competitive edge with the world's advanced economies, unfortunately, evidence from the extant literature has constantly shown a reverse falling trend which calls for an urgent higher education policy intervention among others to boost higher education enrolment. This is with the expectations that it will improve economic growth in the region which in turn will reverse the falling trend in the general economic performance. These SSA countries made little progress in raising their levels of education in general and higher education in particular. This low level of education or higher education is evident in explaining the poor performance of human capital formation (Glewwe, Maiga \& Zheng, 2014). World Bank data estimated that between that same period, 1980 and 2000, the region's average growth rate in GDP per capita the world over was about 3.6\% for South Asia, 0.5\% for Latin America, 4.9\% for East Asia, 1.2\% for Middle East, but a mere $-0.6 \%$ for SSA countries. Low higher education enrolment is hypothesized to be amongst the reasons why SSA countries are experiencing such an abnormally low economic growth. A country's level of education in term of population in general and higher education achievement in particular steadily reveal and reflect the knowledge, skills, and the level of economic growth and freedom enjoyed by the people (Bloom et al., 2014).

Further, the SSA economy has experienced the worst economic performance on record since the last two decades in 2016. Preliminary estimate indicates that the SSA real GDP aggregate increased by $1.1 \%$ in the first quarter of 2016; this immediately followed a correspondingly decline of $1.0 \%$ expansion in the third quarter. Growth is expected as a result of this to drop in 2016 to $1.2 \%$ from the 2015, 3.2\% GDP growth rate. This sharp decline in the GDP growth rate is the SSA's worst economic performance since 1993 (Olamosu \& Wynne, 2015). The reasons for the decline in the SSA GDP growth has to do with the nature of primary 
products and activities such as agrarian agriculture and mining that engage the majority of the citizens in the region which make SSA countries susceptible to external shocks. Low higher education enrolment is hypothesized to be amongst the reasons why SSA countries are experiencing such a low economic growth. Premised upon the above, any attempt to examine and quantify the poor economic performance and low productivity for the purpose of reversing them through a higher educated workforce in SSA economy is a relevant and much needed initiative because these issues are of policy concerns in the region. Hence, to properly address the concerns in this study, the highlights of the study's hypothesis is that there are no significant positive impacts between each level of education and economic growth in the selected SSA countries. To test this hypothesis, Fixed effects least square dummy variables (LSDV) and system GMM are employed as the study's estimating techniques. While the main objective of this paper is to analyse and to compare the effects of various levels of education in the selected Sub-Saharan Africa countries. The sub objectives of this research work are to:

- determine the effects of primary education enrolment and primary education output on the economic growth.

- examine the effects of secondary education enrolment and secondary education output on economic growth.

- investigate the effects of higher education enrolment and higher education output on economic growth.

- compare the effects of the composite model with and without higher education on economic growth.

\section{Literature Review}

Education and Growth: Theoretical Framework: Empirical analyses of education and its comparative impacts on SSA economic growth make sense and they are relevant based on the premise that they adequately relate to human capital-growth theories. Theories that summarize the relevance of education to growth are hereby reviewed. There is a large literature attesting to the impact of education on human capital in the long run growth determination (Lucas, 1988; Shaihani et al., 2011). Solow (1956) developed the neoclassical growth model in which: $Y=A f(K, L)$, where $Y=$ GDP output, $A=$ Total factor productivity (technological change), $K=$ Physical capital, $L=$ Labour. Labour productivity in this theory $=Y / L$, the theory finally concluded that the output of an economy can be determined by the increase in any of the inputs, which leads to equilibrium state. To adequately organise the factor input, Mankiw, Romer \& Weil (1992) were credited for the integration of human capital into the growth model. It has been argued in the theory of economic growth that education-centered human capital impacts on the economic growth as it enters as an input into the production process (Lucas 1988) and by acting as an agent of diffusion, innovation technology, and catch-up processes (Romer, 1990; Nelson \& Phelps, 1966). In the attempt to authenticate the validity of these theories, many empirical works on human capital and growth nexus have been conducted across the regions of the world, and the outcome of their findings appear mixed. The results of some of the researchers are giving below:

Education and Growth: Empirical Analysis: Literatures that established the significance of human capital education on growth is large in both developed and the developing economies. However, only a few empirical works focus on the effects of various levels of education on growth. Presented below are the main works that have investigated the effects of different individual levels of education on economic growth:

Apart from the research conducted by Pegkas (2014) in Greece, much empirical study on these concepts are summarized to establish a link between economic growth and educational levels. Pagkas studies the effects of various levels of educational on Greece GDP's growth for a period of 1960 to 2009. The outcome indicates the presence of a long-run relationship between gross domestic product and various educational levels. The overall findings indicate that higher and secondary education have statistically significant positive effects on the GDP growth, but primary education has no significant impacts on economic growth. Gemmell (1996) conducts an empirical work for the OECD countries, and his findings indicate that while higher and secondary education impact on growth in the developed economies, primary education mostly impact on the less developed nations. For the research carried out by Tallman \& Wang (1994), higher education appears to have higher positive effects on the economic growth of Taiwan compared with secondary and primary education. For a sample of Asian countries, Mc Mahon (1998) investigation of the impacts of three educational levels on economic growth and outcome indicates that while 
higher education negatively impacts on growth, secondary and primary levels have statistically significant positive impacts on economic growth.

The study conducted by Abbas (2001) in Sri Lanka and Pakistan clearly indicates that the economic growth of these countries are negatively impacted by primary education, while higher and secondary education exhibit a statistically significant positive effects on the two countries' economic growth. Petrakis \& Stamatakis (2002) notes that the effects of education on growth depends on the developmental level of the economies; developing nations' economic growth appear to benefit from secondary and primary education whereas highly developed countries gain from higher education. Villa (2005) examines the various impact of each of the three levels of education on Italy's economic growth and the result indicates that education at secondary and higher levels impacts positively on the GDP growth, whereas, result from primary education indicates that it has no significant impacts on growth in Italy. Gyimah, Paddison \& Mitiku (2006) study Africa economies and conclude that the three education levels are statistically significant with a positive effect flowing from education variables to growth in the African countries per-capita income. Regression result on Taiwan according to Lin (2006) indicates that all the three: higher, secondary and primary education, exhibit positive effects on growth in the economy. However, Chi (2008) indicates that higher education has larger and positive effects in China than secondary and primary education has on GDP growth. The outcome of these findings have shown that there are mixed results on the impacts of different levels of education on economic growth in different regions of the world. However, from the review of the extant literatures, it is clear that works on SSA region on this subject matter appear to be very scanty and the debates on the contribution of each level of education on growth is still ongoing. This study, will in this wise, contribute to the growing literature on the impacts of education stock on growth in the SSA region. The section that follows introduces us to the appropriate methodology that will be used to achieve the study's objectives.

\section{Methodology}

Model Specification: The study augments Cobb Douglas' production function for labour input effectiveness given by Bloom et al. (2014) and Holland (2013) where labour force combines with level of human capital $Y_{i t}=A_{i t} K^{\alpha}{ }_{i t}\left(L_{i t} V_{i t}\right)^{\beta}$

Where:

$Y_{i t}=$ Total output in country $i$ at time $t$.

$A_{i t}=$ TFP in country $i$ at time $t$.(In this model, $\mathrm{A}_{\mathrm{it}}$ is assumed constant as parametric efficiency)

$K_{i t}=$ Physical capital in country $i$ at time $t$.

$L_{i t}=$ Labour force in country $i$ at time $t$.

$V_{i t}=$ Level of human capital per worker in country $i$ at time $t$.

$\left(L_{i t} V_{i t}\right)=$ Labour input effectiveness

$\alpha$ and $\beta=$ partial elasticity coefficient of output with respect to physical and human capital in country $i$ at time t. Where $\alpha+\beta \leq 1$ (Bloom et. al,2014)

To disaggregating $V_{i t}$ into:

$V_{i t}=\left(\right.$ Per $_{i t}$ Pot $_{i t}$ See $_{i t}$ Sot $_{i t}$ Ter $_{i t}$ Tou $\left._{i t}\right)$

Where

$P^{P e r}{ }_{i t}=$ Primary school enrolment in country $i$ at time $t$.

Pot $_{i t}=$ Primary school output in country $i$ at time $t$.

$S e e_{i t}=$ Secondary school enrolment in country $i$ at time $t$.

Sot $_{i t}=$ Secondary school output in country $i$ at time $t$.

$T r_{i t}=$ Higher education school enrolment in country $i$ at time $t$.

$T u_{i t}=$ Higher education school output in country $i$ at time $t$.

$Y_{i t}=A_{i t} K_{i t}^{\alpha}\left(L_{i t} \text { Per }_{i t} \text { Pot }_{i t}, \text { See }_{i t} \text { Sot }_{i t}, \text { Ter }_{i t}, \text { Tou }_{i t}\right)^{\beta}$

To take the log of Equation (5)

$\log Y_{i t}=\log A_{i t}+\alpha \log K_{i t}+\beta\left(\log L_{i t}+\log P_{e r} r_{i t}\right.$

$\log \mathrm{Pot}_{i t} \log \mathrm{See}_{i t}+\log \mathrm{Sot}_{i t}+\log \mathrm{Ter}_{i t}+\log \mathrm{Tou}_{i t}$ )

In summary, the production function aggregate when linearised can be expressed thus:

$\log Y_{i t}=\log A_{i t}+\alpha \log K_{i t}+\beta \log L_{i t}+\beta \log P e r_{i t}+$

$\beta \log \mathrm{Pot}_{i t}+\beta \operatorname{logSee}{ }_{i t}+\beta \log \mathrm{Sot}_{i t}+\beta \log \mathrm{Ter}_{i t}+\beta \log \mathrm{Tou}_{i t}$ 
The study introduces $\mu_{i t}$, to capture the unexplained phenomenon(random shock) which was not captured in the adjustment process and this is a composite error which consists of a country's specific component $\eta_{\mathrm{i}}$, and time component $\varepsilon_{t}$ and idiosyncratic component $\delta_{i t}$. The summary expression of this composite error $\mu_{i t}=\eta_{i}$ $+\varepsilon_{t}+\delta_{\text {it }}$ $Y_{i t}=\log A_{i t}+\alpha \log K_{i t}+\left(\beta \log L_{i t}+\beta \log P e r_{i t}+\beta \log P o t_{i t}+\beta \operatorname{logSee}{ }_{i t}+\right.$ $\beta \log$ Sot $_{i t}+\beta \log$ Ter $_{i t}+\beta \log$ Tou $\left._{i t}\right)+\mu_{i t}$.

In order to build a dynamic model into the system, as earlier done for other levels of education, we introduce the lag of dependent variable to the right hand side (Roodman,2009; Bloom et al., 2014).

$y_{i t}=a_{i t}+y_{i t-1}+\alpha k_{i t}+\beta l_{i t}+\beta \log P_{e r} r_{i t}+\beta \log t_{i t}+\beta \operatorname{logSe}{ }_{i t}+$

$\beta \operatorname{logSot}_{i t}+\beta \log \mathrm{Ter}_{i t}+\beta \log \mathrm{Tou}_{i t}+\mu_{i t}$

The $y_{i t}, k_{i t}, l_{i t}$, per $_{i t}$ pot $_{i,}$, Se $_{i t}$, sot $_{i t}$, ter $_{i t}$, tou $_{i t}$ are the logs of $Y_{i t}, K_{i t}, L_{i t}$, Per $_{i t}$, Pot $_{i t}$, See $_{i t}$, Sot $_{i t}$ Ter $_{i t}$, Tou $_{i t}$ respective

Justification of estimating technique: Basically, this paper shall adopt two models in the Panel estimation: The first is the static panel model and the other is the dynamics panel model (Bai, 2009).

The summary fixed effect equation is given as:

$Y_{i t}=X_{i t} \beta+\pi_{i}+\mu_{i t}$

Here, intercept is missing, $y_{i t}$ is the vector of log difference of GDP across the SSA countries. The unobserved country-specific effect is $\pi_{i}, \beta$ is a vector of estimating parameter for each of the explanatory variables while constant $x_{i t}$, is K-dimensional row vector of explanatory variables $\log A_{i t}+\log K_{i t}+\left(\log L_{i t}+\log P_{i t}+\log P_{i t} t_{i t}\right.$ $\operatorname{logSee}_{i t}+\log \mathrm{Sot}_{i t}+\log \mathrm{Ter}_{i t}+\log \mathrm{Tou}_{i t}$ ) over the observable time period of the variables under investigation, while $\mu_{i t}$ is the stochastic error term.

For the LSDV equation, we have the following:

$y_{i t}=\sum_{j=2}^{4} D_{j}+X_{i t} \beta+\pi_{i}+\mu_{i t}$

In equation (12), $D_{j}$ represents the dummy variables for $\mathrm{N}-1$ cross section of countries.

The equation which addresses random effect model condition is hereby submitted as follows:

$y_{i t}=\alpha+X_{i t} \beta+\pi_{i}+\mu_{i t}$

Where $y_{i t}$ is a vector of log difference of GDP across the SSA countries, $\alpha$ is the constant, $\beta$ is a vector of parameter estimates for each of the explanatory variables, $x_{i t}$ is a K-dimensional row vector of explanatory

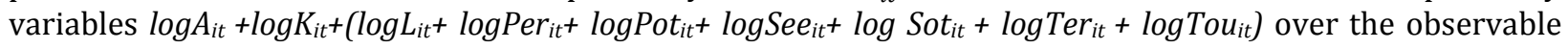
time period of the variables under investigation, while $\mu_{i t}$ is the between-entity error. $\pi_{i}$ is within-entity error. In the estimation of random effects $\pi_{i}$ is assumed to be random which will be uncorrelated with the model explanatory variables.

The preferences for fixed effects or random effects model cannot be taken at random: thus, Hausman (1978) test is introduced in this study.

Again, dynamic panel data approach (Arellano \&Bond, 1991) popularly known as generalized method of moments (GMM) is also adopted in this study. This type of estimating technique generates a model that improves the efficiency of the estimator.

The equation of the GMM is thus:

$y_{i t}=X_{i t} \beta_{1}+W_{i t} \beta_{2}+\varepsilon_{i t}$

Where $y_{i t}$ is the vector of log difference of GDP across the SSA countries, $W_{i t}$ is the vector of pre-determined regressors including lag(s) of $\mathrm{y}$, intercept, $\beta_{i}$ for $i=1,2$ are parameter estimates for each of the explanatory variables, $x_{i t}$ is a K-dimensional row vector of strictly exogenous explanatory variables over the time period that are observed, and $\varepsilon_{i t}=\pi_{i}+\mu_{i t}$ is the error term.

This equation is just a modification of the fixed effect equation with the inclusion of instrumental variables.

\section{Data and Empirical Analysis}

Data Sources: The study adopts data for 30 SSA countries over 1980-2015 period and follows the usual practice in the empirical growth literature by taking interpolation of the five years variable (Tang et al., 2008). Data set for variables on enrolment rates for primary, secondary and higher education, completion rates on primary, secondary and higher education are available in Baro and Lee (2013) data sets to cover the period 1980-2010 while the data to cover the period 2015 are available in the new version of Baro and Lee (2015-2040) data sets.Data on GDP per capita are sourced from the online version of World Bank database. 
Employment rates and capital stock are taken from the Penn World Table 9.0 (Feenstra Robert \& Marcel, 2015).

Data Analysis and Interpretation: This section addresses the analysis of data and the results of our findings are reported accordingly.

Result of Summary Statistics: The result from summary statistics clusters around its mean which indicates how education variables and economic growth interacts in the model. It is obvious from the summary statistics that the growth rates of GDP, capital stock and employment rates are all nearer the minimum value than its maximum, it simply indicates that these three variables are relatively low during the sample period; whereas primary school enrolment and output have their values closer to the maximum than the minimum indicating that enrolment and its output rate are fairly higher during the sampled time. Also, the result from summary statistics establishes the claims from the observation of Atardi and Sala-i-Martin (2003), that Africa's growth has been nothing but tragic. On the other hand, the result supports the argument from the United Nation (2012) that enrolment in the region for primary education is high but the dropout rate is also high and this is reflected in the result obtained from primary output.

Table 1: Summary statistic Result

\begin{tabular}{llllll}
\hline VARIABLES & Obs & Mean & Std. Dev & Min & Max \\
\hline Rgdpna & 1020 & 9.431441 & 1.189602 & 5.817422 & 13.3938 \\
Ck & 1020 & 9.999421 & 1.34196 & 6.99979 & 14.61521 \\
Emp & 1020 & 3.83313 & 4.098003 & .1198697 & 24.2509 \\
Per & 1020 & .1026893 & 1.175333 & -17.97 & 17.5 \\
Pot & 1020 & .2319433 & .5861138 & -4.087428 & 4.41 \\
See & 1020 & .6526353 & 1.259034 & -25.47 & 7.25 \\
Sot & 1020 & .3092945 & .7612114 & -5.534075 & 6.79 \\
Ter & 1080 & 0.56218 & 0,1983102 & -1.57 & 2.6 \\
Tou & 1080 & .295786 & .9836313 & -.98 & 1.33 \\
\hline
\end{tabular}

Source: Authors' Computation, 2017

Table 2: Correlation Matrix

\begin{tabular}{|c|c|c|c|c|c|c|c|c|c|}
\hline & Rgdpna & Ck & Emp & Ter & Tou & See & Sot & Per & Pot \\
\hline Rgdpna & 1.0000 & & & & & & & & \\
\hline $\mathrm{Ck}$ & 0.8978 & 1.0000 & & & & & & & \\
\hline Emp & 0,7038 & 0.6656 & 1.0000 & & & & & & \\
\hline Per & -0.0967 & -0.1048 & -0.0012 & 1.0000 & & & & & \\
\hline Pot & -0.1253 & -0.1143 & -0.0408 & 0.2590 & 1.0000 & & & & \\
\hline See & 0.1439 & 0.1366 & 0.0250 & $-\overline{0.5433}$ & -0.1447 & 1.0000 & & & \\
\hline Sot & 0.2478 & 0.2341 & 0.1627 & $-\overline{0.3010}$ & 0.0191 & 0.2350 & 1.0000 & & \\
\hline Ter & 0.0402 & 0.0359 & -0.0224 & 0.4098 & 0.0663 & $-\overline{0.2433}$ & 0.0355 & 1.0000 & \\
\hline Tou & 0.0214 & 0.0232 & -0.0218 & 0.4715 & 0.0051 & 0.2115 & 0.0506 & 0.9469 & 1.0000 \\
\hline
\end{tabular}

Source: Authors' Computation, 2017

Again, for secondary school enrolment, it is evident from the result of the summary statistics that there is a relatively high enrolment in this level of education, but not as high as that of primary enrolment. This now corroborates the initial result obtained that there is a higher dropout rate in the primary education and this could account for why enrolment is low in this level of education. This again supports the statistics that while SSA region is recording $72 \%$ in the primary education, secondary school has an average enrolment of $40 \%$ (United Nation, 2012). Again, secondary school output appears more favorable as the result from summary statistics shows that output is nearer the maximum than the minimum. Finally, the summary statistics result on higher education indicates that both the enrolment and output are fairly high in the SSA countries under 
investigation. This is clearly seen as both values obtained are nearer the maximum than the minimum very slightly.

This section reports the result of the correlation matrix on the relationship between the behavioral and outcome variables without indicating the direction, size or nature of relationship. The study discovers a strong relationship between real Gdpna and capital stock, as well as real Gdpna and employment rate at the value of $0.8969,0.7063$ respectively. Again, a similar strong value of 0.6723 is obtained for the relationship between capital and employment rate. This result indicates a strong association-ship among the variables. Table 3.2 further offers explanation on the relationship between primary enrolments with its output on real Gdp growth which are the variables of interest; all signs are not expected as both variables are inversely related to growth. However, progression to education variable shows that the relationship between primary school enrolment, primary school output, employment, and capital stock are both weak and negative, except for primary school enrolment and primary school output which are positive but weak. The negative and weak results among these variables reflect the SSA situations. The next rung of education ladder is the secondary education which indicates an improvement in relationship. For instance, a positive but weak relationship exists between real Gdp growth with both secondary school enrolment and output. Similar relationship is obtainable from secondary school enrolment and its output to capital stock and employment rate. Finally, the study further observes a weak relationship between secondary enrolment and its output. The highest in the rung of education ladder is the higher education and the summary result again shows a positive but weak relationship between real Gdp growth with higher education enrolment and its output whereas Capital stock exhibits positive but weak relationship with higher education enrolment and its output. Finally, it is clear from the outcome of this result that there is a very strong relationship between higher education enrolment and its output. Having conducted the summary statistics and the correlation matrix to determine the nature of relationship among the study's variables, the study proceeds to test the appropriate relationship by adopting fixed effects LSDV and dynamic analysis.

\section{Table 3: Fixed effects (Within) Regression Result}

Ho: Random effects model is appropriate

Ha: Fixed effects model is preferred

\begin{tabular}{|c|c|c|c|c|}
\hline \multicolumn{2}{|c|}{$\begin{array}{l}\text { R-sq: } \text { within }=0.7214 \\
\text { between }=0.8595 \\
\text { overall }=0.8204\end{array}$} & & \multicolumn{2}{|c|}{$\begin{array}{l}F(8,1042)=337.19 \\
\text { Prob }>F=0.0000 \\
\text { Number of obs }=1080\end{array}$} \\
\hline Rgdpna & Coefficient & Standard error & $t$ & $\mathbf{P}>|\mathbf{t}|$ \\
\hline $\mathrm{Ck}$ & .4033695 & .0106346 & 37.93 & 0.000 \\
\hline Emp & .0609004 & .0048363 & 12.59 & 0.000 \\
\hline Per & .0437874 & .0094491 & 4.63 & 0.000 \\
\hline Pot & -.0091575 & .0142508 & -0.64 & 0.521 \\
\hline See & .0245043 & .0070012 & 3.50 & 0.000 \\
\hline Sot & .0245987 & .0109119 & 2.25 & 0.024 \\
\hline Ter & .5089796 & .1285789 & 3.96 & 0.000 \\
\hline Tou & -1.106622 & .2740701 & -4.04 & 0.000 \\
\hline Cons & 5.142788 & .0991435 & 51.87 & 0.000 \\
\hline
\end{tabular}

This section, as indicated in Tables 4.3 and 4.4, contains the result in the panel model. The study reports the result from both fixed and random effects. It further investigates through the Hausman test the most appropriate model to be selected and the result from Hausman test shows that there is no significant difference between the two models, even though from the result of the Hausman test, null hypothesis (Ho) is accepted which indicates that random effects model is the appropriate model to be adopted, and since there is no significant difference, we accept the fixed effects model as being an appropriate model too. The adoption of fixed and random model is premised upon justification that they can handle heterogeneity effect that may influence the outcome of our findings. All the same, all the significant variables found in the random effects model are also found to be significant in the fixed effects model; the signs and sizes of coefficients from both models are relatively the same. In both models, the following variables, namely: capital stock, employment rates, primary school output, secondary school enrolment and output, higher education enrolment and output evidently seem to be significant. The primary school enrolment that is not significant in the fixed 
effects is also not significant in random effects model. Again, capital stock, employment rates, primary school enrolment, secondary school enrolment and its output, and higher education enrolment are all positively signed in both models, while primary school output and higher education output are also found to be inversely related to growth in both models. The outcome of these results suggests the nature of the relationship (that is, direct or inverse) between each of the significant variables and GDP growth. There is a clear indication that these macro-economic variables are likely to be important determinants of economic growth among the SSA countries under investigation. However, to establish their individual effect in this study, the dynamic panel model is significantly important.

Table 4: Random-effects GLS Regression Result

Ho: Random effects model is appropriate

Ha: Fixed effects model is preferred

\begin{tabular}{|c|c|c|c|c|}
\hline \multicolumn{2}{|c|}{$\begin{array}{l}\text { R-sq: within }=0.7213 \\
\text { between }=0.8590 \\
\text { overall }=0.8203 \\
=2792.75\end{array}$} & \multirow[t]{2}{*}{ Wald chi2(8) } & \multicolumn{2}{|c|}{ Number of obs $=1080$} \\
\hline Rgdpna & Coefficient & & $\mathbf{t}$ & $\mathbf{P}>|\mathbf{t}|$ \\
\hline $\mathrm{Ck}$ & .4089648 & .0107012 & 38.22 & 0.000 \\
\hline Emp & .0625239 & .0048045 & 13.01 & 0.000 \\
\hline Per & .0439565 & .0095602 & 4.60 & 0.000 \\
\hline Pot & -.0117276 & .0144075 & -0.81 & 0.416 \\
\hline See & .024586 & .0070849 & 3.47 & 0.001 \\
\hline Sot & .0255826 & .0110373 & 2.32 & 0.020 \\
\hline Ter & .5360257 & 1298782 & 4.13 & 0.000 \\
\hline Tou & -1.161027 & .276829 & -4.19 & 0.000 \\
\hline Cons & 5.080851 & .1254958 & 40.49 & 0.000 \\
\hline
\end{tabular}

Source: Authors' Computation, 2017

The R-square is good in the two models. This is because at least, all the explanatory variables account for above $70 \%$ variation in the GDP growth among the SSA countries under investigation. The two models are tested for overall significance to corroborate the R-square results through the chi square test for the random effects and F-test for fixed effects. The outcome of our results indicates that both models pass the overall significance test. There is a clear indication from our results so far that the choice of variables adopted in this study appears to be appropriate. In addition, empirical literature indicates the possible tendencies of crosssectional dependence in panel results, and this compels us in this study to conduct the test of significant differences in intercepts among the SSA countries by adopting fixed effects LSDV as indicated.

Table (5) reports the comparative outcome of result from the three levels of education for the 30 countries under investigation. The aim of this section of the study is to show the significant comparative effects of each level of education enrolment and output on the GDP growth rate equation in SSA countries. The analysis attempts to estimate the GDP growth equation first without higher education and secondary education; second, without higher education and primary education and lastly without primary and secondary education and compared the outcome of the equations. The coefficients on primary, secondary and higher education in this equation may offer explanatory indication of how much each level of education may lead to an underestimation of the growth effects of higher, secondary and primary education. The estimate coefficients of these growth equations are appropriately submitted in the columns. Indication from dynamic regression statistics (being a corrective measure of static model) establishes that the estimates are robust and satisfactory. The fixed effects (LSDV) results of higher education are found in columns 2 and 3. Columns 4 and5 are the outcome results of secondary school education (both enrolment and outcome). The final columns 6 and 7 are the results from primary education (both enrolment and output). The table statistics has been done for the purpose of statistical comparison. The study reports the results from both the fixed effects within regression and the dynamic SYSTEM GMM because the results complement each other. The reference point of how significantly higher is in the GDP growth rate equation in the SSA countries which emerges when we compare the estimates in the growth equation with higher education with the estimates without it in the growth equation. 
Table 5: LSDV fixed effects: A Comparative Statistics Analysis of each Level of Education

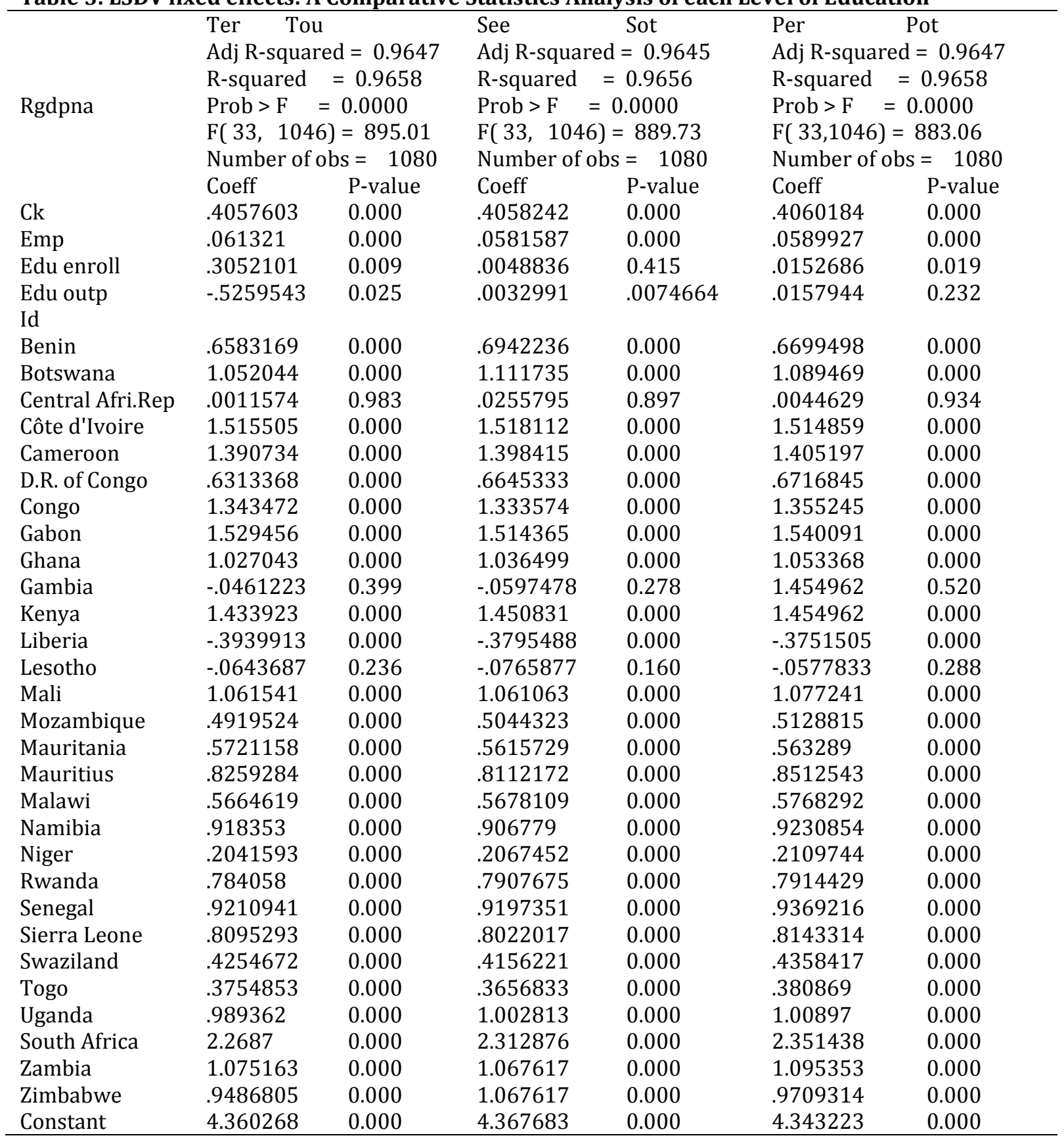

Source: Authors' Computation, 2017

From the exclusive regression of the first level of education in the statistical growth model, the outcome of the study's result shows evidently that capital stock, employment rates and primary education are all statistically significant at $1 \%$ level of significance, however, primary school output is not found to be statistically significant. Positive relationship exists between capital stock and GDP growth. A 1\% increase in the capital stock will cause 38\% increase in the GDP in the SSA countries under investigation. Employment rates have a positive relationship with the growth of the economy in that about $6.3 \%$ increase is expected in the economy as a result of 1 unit increase in the employment rates. Our results also reveal that there is a positive and significant impact of primary school enrolment on the growth of the economy in the region because a $1.52 \%$ increase in the economy is expected as a result of a unit increase in primary education enrolment. However, the primary school output is found not to be statistically significant. As the regression enters a higher rung of 
secondary school ladder, the result reveals that secondary enrolment is not statistically significant while secondary school output is statistically significant to growth. It shows that the student graduates in the second rung of education ladder are not doing enough to influence growth in the economy of the SSA countries being investigated. Higher education is the apex in the rung of education and the findings from this study reveal that when only higher education enrolment and output enter into the regression with capital and labor, higher education enrolment and output are found to be statistically significant along with employment rates and capital stock. While the enrolment coefficient is positive, the coefficient of higher education output is negative. While an increase in enrolment will bring about growth in the SSA region under investigation, output from higher education so far has been seen to inversely impact on growth.

The study further regresses all various levels of education and the result takes a new look. All levels of education including higher education enrolment and higher education output are found to be statistically significant except primary enrolment and apart from the fact that their coefficients show positive relationship with economic growth, the value of their contribution significantly increases. For instance, the percentage of increase is as follows: Primary enrolment (67\%), secondary enrolment $(87.5 \%)$, and Secondary output (123\%), and employment rates $(6.4 \%)$ however, the value of capital stock remains relatively unchanged. The study takes further steps to consider the impacts of education level on economic growth with special emphasis on higher education. The result is hereby submitted in Table 6

Table 6: Dynamic panel-data estimation, two step system GMM

\begin{tabular}{|c|c|c|c|c|}
\hline \multirow{6}{*}{$\begin{array}{l}\text { Number of instrument } \\
\text { Number of obs } \\
\text { Wald chi2 }(9) \\
\text { Time variable } \\
\text { Number of group } \\
\text { Prob> chi2 }\end{array}$} & & & \multicolumn{2}{|l|}{27} \\
\hline & & & 1950 & \\
\hline & & & 16092.8 & \\
\hline & & & Yearly & \\
\hline & & & 30 & \\
\hline & & & 0.0000 & \\
\hline Variables & Coefficient & Stand. Err. & Z-Stat & P-Value \\
\hline Rgdpna (L1) & 1.029873 & .0170934 & 60.25 & 0.000 \\
\hline Tou & 2.610751 & 1.105494 & 2.36 & 0.018 \\
\hline Ter & -1.288569 & .5169781 & -2.49 & 0.013 \\
\hline Sot & -.1133662 & .0476968 & -2.38 & 0.017 \\
\hline Per & -.0390657 & .0254622 & -1.53 & 0.125 \\
\hline Pot & -.0369265 & .0282777 & -1.31 & 0.192 \\
\hline Emp & .007077 & .008333 & 0.85 & 0.396 \\
\hline Ck & -.0127923 & .010278 & -1.24 & 0.213 \\
\hline Cons & -.0992949 & .1508003 & -0.66 & 0.510 \\
\hline
\end{tabular}

Source: Authors' Computation, 2017

The result of the SYS GMM in Table 4.6 incorporates all the levels of education into the dynamic model and from the findings, higher education enrolment and its output maintain consistency in its statistical significance, magnitude and the direction of coefficient. The lag value of the Gdpna maintains a consistent positive relationship with the Gdpna. Again, higher education enrolment, higher education output and secondary school output are all statistically significant. The result of this model reverses signs of the coefficients for higher education. Here, higher education enrolment and secondary school output are inversely related to Gdpna, whereas higher education output has positive relationship with Gdpna. Primary school output, secondary school enrolment together with employment rate and capital stock are not statistically significant to impact growth on the economies of SSA countries under investigation.

In this dynamic model, only few of the variables that are found to be statistically significant in the static panel model are significant in the SYS GMM. All the levels of education are cumulated into the model to study how the model behaves. The SYS GMM result indicates that higher education enrolment and its output, the lag value of GDP growth rate and secondary school output may constitute major determinants of economic growth in the SSA countries. A growing reversed relationship of Ter and Sot stunts and inhibits growth as this section of the economy appears to absorb expenditure rather than contributing to the economy. There is a high tendency for allocated resources to be trapped with unproductive economic agents. When those 
secondary school output enter into higher education for enrolment at this level, enrolment remains unproductive until they turn out to become higher education output. With likely associated income rise as higher education joins real sector, financial capacity which reduces economic burden is enhanced and this in turn is expected to reduce the level of growth rate of the economy in the previous year but since this lag period is found to be positively significant, it indicates that a consistent growth rate is required flowing from the past in determining the current GDP growth level in SSA countries under review. In conclusion, Ter and its output, Sot and the current GDP levels are major variables that could have individual significant effects on the magnitude of the SSA countries. However, we need to conduct some tests on these results in order to ascertain their validity. Dynamic panel-data estimation, two step system GMM (Robust) is employed to control for standard covariance matrix robustness in heteroskedasticity and autocorrolation ,that is, panelspecific, and to avoid standard errors that are downward biased, two step robust is adopted to get the finite sampled corrected for two-step covariance matrix.

\section{Table 7: Sargan test of over-identifying restrictions}

$\begin{array}{ll}\text { H0: over-identifying restrictions are valid } & \\ \text { chi2(18) } & 1.53 \\ \text { Prob }>\text { chi2 } & 1.000\end{array}$

Source: Authors' Computation, 2017

\section{Table 8: Hansen test of over-identifying restrictions}

$\begin{array}{ll}\text { H0: over-identifying restrictions are valid } & \\ \text { chi2(18) } & 14.40 \\ \text { Prob }>\text { chi2 } & 0.703\end{array}$

Source: Authors' Computation, 2017

Sargan /Hansen Test of Over-Identifying Restrictions Result: This study applies robust estimation where both Hansen and Sargan statistics are reported, and the normal rule of thumb is that Sargan test has a null hypothesis of "the instruments as a group are exogenous". Therefore, the higher the p-value of the Sargan or Hansen statistics, the better. Therefore, Null hypothesis is rejected as the instruments as a group is strictly not exogenous. This shows that over-identifying restrictions are invalid and the implication is that the number of instruments used in the SYSGMM estimation does not have any negative effect on the estimators of the SYSGMM.

\section{Table 9: showing test for serial correlation}

\begin{tabular}{lll}
\hline $\mathrm{H}_{0}=$ no autocorrelation & & \\
Arellano-Bond test for AR(1) & $\mathrm{z}=-2.41$ & $\mathrm{Pr}>\mathrm{z}=0.016$ \\
Arellano-Bond test for AR(2) & $\mathrm{z}=-0.42$ & $\mathrm{Pr}>\mathrm{z}=0.932$ \\
\hline
\end{tabular}

Source: Authors' Computation, 2017

Again, Arellano-Bond test for autocorrelation has a null hypothesis of no autocorrelation. The rule of thumb here is that AR2 must not be significant. The significant value of AR1 indicates that there is the presence of autocorrelation which, however, is being corrected at AR2. Null hypothesis is rejected at $5 \%$ level of significance.

This section further investigates the pattern of behavior in the growth equation when higher education variables are not included in the dynamic model. In this section, all the levels of education are cumulated into the model to study how the model behaves. However, higher education is missing in this model. The SYS GMM result indicates that primary education enrolment and its output, the lag value of GDP growth rate and employment rates may constitute major determinants of economic growth in the SSA countries. Our findings further confirm the initial postulations that primary education is enough without higher education to promote growth. This wrong notion keeps the sub- Sahara countries as primary producer of Agricultural products at the expense of knowledge based technological innovations. There is a puzzling challenge in the magnitude and the direction of the coefficients. As noted in the Table, while enrolment impacts positively, primary output and employment rates do not. It is evident from the foregoing that an increase from the graduating students of primary school would not impact on growth as an average primary school output would not seek any economic benefit other than seeking the next level of education. 
Table 10: Dynamic panel-data estimation, two step system GMM

\begin{tabular}{|c|c|c|c|c|}
\hline \multicolumn{3}{|c|}{ Number of instruments } & \multicolumn{2}{|l|}{13} \\
\hline \multicolumn{3}{|c|}{ Number of obs } & \multicolumn{2}{|l|}{1950} \\
\hline \multicolumn{3}{|c|}{ Wald chi2(9) } & \multicolumn{2}{|l|}{14532.26} \\
\hline \multicolumn{3}{|c|}{ Time variable } & \multicolumn{2}{|l|}{ Year } \\
\hline \multicolumn{3}{|c|}{ Number of group } & \multicolumn{2}{|l|}{30} \\
\hline \multicolumn{3}{|l|}{ Prob>chi2 } & \multicolumn{2}{|l|}{0.0000} \\
\hline Variable & Coefficient & Stand. Err & Z.Stat & P-Value \\
\hline Rgdpna L1 & 1.179709 & .1189392 & 9.92 & 0.000 \\
\hline See & .032181 & .1108731 & 0.29 & 0.772 \\
\hline Sot & .0358628 & 0991891 & 0.36 & 0.718 \\
\hline Per & .3801952 & 1509535 & 2.52 & 0.012 \\
\hline Pot & -.4217374 & .1633182 & -2.58 & 0.010 \\
\hline Emp & -.008596 & .0047573 & -1.81 & 0.071 \\
\hline Ck & -.1370651 & .1185192 & -1.16 & 0.247 \\
\hline Cons & -.2220765 & .1586485 & -1.40 & 0.162 \\
\hline
\end{tabular}

Source: Authors' Computation, 2017

Table 11: Sargan test of over-identifying restrictions

H0: over-identifying restrictions are valid

$\begin{array}{ll}\text { chi2(5) } & =0.39\end{array}$

Prob > chi2 0.996

Table 12: Hansen test of over-identifying restrictions

H0: over-identifying restrictions are valid

chi2(5) 1.96

Prob > chi2 0.854

Table 13: Result of Serial Correlation

$\mathrm{H}_{0}=$ no autocorrelation

Arellano-Bond test for AR(1) $\quad \mathrm{z}=-1.8 \quad \operatorname{Pr}>\mathrm{z}=0.073$

Arellano-Bond test for AR(2) $\quad \mathrm{z}=0.89 \quad \operatorname{Pr}>\mathrm{z}=0.371$

Finally, the result shows that the null hypothesis is rejected; therefore, over-identifying restrictions are invalid. The implication is that the number of instruments used in the SYSGMM estimation does not have any negative effect on the estimators of the SYSGMM. The closer the P- value to one, the better, thus, the result is adequate to establish no over identifying restriction. Again, the number of instruments does not exceed the number of countries. Based on the model diagnostics, the Arellano-Bond SYSGMM estimator produces the best estimates at AR (2); at the level of AR (1) estimation, a level of serial correlation could be expected which is being corrected at AR (2), therefore, the level of significance may be allowed at AR(1) but not at AR(2). Again, the number of instruments is less than the number of groups and finally, the overall p-value is strongly significant.

Inferences, Comparisons with Previous Empirical Studies and Discussion of Findings: In this study, the significant statistical impacts of higher education (both higher education enrolment and output) on SSA countries under investigation when compared with other levels of education appear obvious and the result remains consistent all through the analysis with some adjustments in the dynamic results. The cumulative impacts of each level of education increase as they combine to impact on economic growth. For instance, Ter increases Gdpna by 31\% and Tou decreases Gdpna by 53\% when regressed alone against Gdpna. The Tervalue impacts, on the other hand, increases to $51 \%$ on Gdpna and Tou impact decreases to $11.1 \%$ when it combines with other levels of education. A comparable figure is the See and Sot whose impact value in growth regression model alone increases Gdpna by 5\% and 3\% respectively. This impact value increases to $25 \%$ for See and $25 \%$ for Sot when combined together with other education variables in the regression. The increasing impact value of Per is $6 \%$ and Potis $1.5 \%$ on Gdpna when regressed against Gdpna. When this first level of education combines with other levels, a new impact of $4.3 \%$ is experienced with inverse impact of $0.9 \%$ decrease in Gdpna as a result of $1 \%$ increase in Pot. 
However, the more robust system GMM offers contrasting result as only higher education output has positive relationship with economic growth when all the education variables enter the regression growth model. A superficial look at this result appears to negate a priori expectations as we would expect positive relationship to flow from lower levels of education to Gdpna; although authors such as Shaihani et al. (2011); Voon (2001) and Agiomirgianaskis, Asteriou \& Monasitiriotis (2002) note that the higher the education level (higher, secondary and primary), the more the impact of education on growth. Bloom et al. (2014) and Appiah and McMahon (2002) also obtain similar result, however, authors such as Petrakis \& Stamatakis (2002) and Anyanwu et al. (2007) found a contradicting result. However, theories on the relationship between human capital educations appear to have mixed explanations on the outcome of this finding. Examples of such theories are Nelson \& Phelp (1966) who argue on education and externality theory that the only way by which education can impact on growth is through technology (which primary and secondary lacks in the SSA countries). Krueger \& Lindahl (2000) postulate the possibility under which social return to education will be lower than individual return. From their own point of view, education is all about certification which does not result in productivity growth effects. Parallel to this theory is human capital-growth theory which argues that a highly education-centered human capital impacts on economic growth by functioning as an input in the production process (Lucas, 1988; Mankiw, Romer \& Weil, 1992). It appears that the dynamic result is a true reflection of SSA countries under investigation based on the following facts: the structure of primary and secondary education among SSA countries was not tailored towards having immediate impacts on the growth of the region's economy; however, as higher education produces her output, the transmission mechanism effects lead to economic growth. Again, due to advancement in statistical methods, it appears that statistical relationship between human capital and growth reduces with the signs parameter changing over time. Another observed possible cause is the extent of significance of human capital. Human capital marginal return appears to be large in the economies where there is scarcity of it. The study obtains further possible reasons from Jones (1996) who postulates that it is not changes in the percentage of attainment in education that matters, or the means by which education is allowed to enter the regression model, but rather the level changes. Again, Petrakis \& Stamatakis (2002) argue that the growth effect of higher education is a function of development level in the economy and that while we expect higher education to negatively contribute to growth in the developing economy, the reverse holds for developed economies. The result of this study refutes this claim.

\section{Conclusion}

The result from the SYSTEM GMM analysis shows that higher education could be more important for growth in the SSA countries than investment in physical capital and other levels of education. The result from higher education showing positive relationship with economic growth is supported both theoretically and empirically from studies conducted by other researchers in countries across other regions of the world. Perhaps, the relatively high growth effects of higher education human capital could be as a result of the fact that SSA has a comparatively very low higher education stocks, thereby, causing the marginal contribution to GDP growth to be relatively high. Given the diagnostic check conducted in this study, the robustness of our findings has been established. The hypothesis of this study indicating that there are no significant positive impacts between each level of education and economic growth in the selected SSA countries has been proved. The growth effects of each level of education are areas that have been extensively explored in the literature. Our study, however, contributes to the literature on SSA in three ways. First, the study integrates primary enrolment and its output; secondary enrolment and its output; higher education enrolment and its output growth effects model which before now have been used individually. This has enabled us to highlight dropout rate as the possible reasons for the divergent results in the literature on the relationship between each level of education and its corresponding output which no author has accounted for. To the best of our knowledge, this is the first study that integrates these two concepts. Second, we provide evidence to support negative relationship between lower rungs of education and economic growth, as well as positive relationship between higher education and economic growth.

Lastly, this study provides evidence that increasing contribution of each level of education on growth when they all combine together is more evidenced than when each level is regressed against growth individually. Thus, this study, contributes to the economic science by filling the gap in the extant empirical literature accordingly. The major constraints in the study is the limited availability of education data which is available 
for only thirty countries of the SSA region and to use the result of thirty out of the forty-six countries available in the World Bank development indicator to generalize the situations in SSA as a region is contestable and opens the study to critical debates. This is an unavoidable limitation to the study. There is also the tendency to overestimate the impacts of higher education while those of primary and secondary education on economic growth are underestimated since the primary and secondary education are not significant in the growth equation. Any individual that has obtained higher education must have obtained certain years of secondary and primary education. From conventional definition, the estimation of higher education cumulatively must have added lower rung of education, hence, overstatement of the growth impacts of higher education could have resulted from the coefficient of higher education. By necessary implication, elements of primary and secondary education must be contained in higher education. The extent to which overstatement of the higher education coefficient affects growth cannot be known precisely. The growth equation has been explored and compared between when higher education was included and when only primary and secondary regressors are estimated. This result has been compared with SYSGMM result. The significant variation in the higher education coefficient in the study's regression analysis could offer information on the size and direction of this possible bias. In column 2 , the estimated results are presented.

Based on the result obtained from the SYSGMM analysis, only higher education enrolment, higher education output and secondary school enrolment are statistically significant at 5\% level of significance while capital stock is not statistically significant. While the coefficient of higher education output is positive, showing the positive impact of higher education on growth, the coefficients of higher education enrolment and secondary school output are negative. From the foregoing results of contribution of higher education on SSA growth, it is evidenced that higher education through her transmission mechanism impacts more on SSA economic growth in comparison to other levels of education. This could not be unconnected to its productivity, innovation, technology and special skill acquisition role which cannot be acquired in the lower level of education. This study suggests a strong policy support for higher education in SSA countries; if higher education is adequately supported through programs enhancing innovation, technology and special skill acquisition it would improve the SSA economic growth.

\section{References}

Abbas, Q. (2001). Endogenous Growth and Human Capital: A Comparative Study of Pakistan and Sri Lanka. The Pakistan Development Review, 40(4), 987-1007.

Agiomirgianaskis, G., Asterious, D. \& Monastiriotis, V. (2002). Human Capital and Economic Growth Revisited: a Dynamic Panel data study. Journal of International Advances in Economic Research, 8(3), 177187,doi: https ://doi. org/10.1007/ bf02 297955

Anyanwu, J. \& Erhijakpor, A. E. (2007). Working Paper 92-Education Expenditures and School Enrolment in Africa: Illustrations from Nigeria and Other SANE Countries (No. 227). https://ideas.repec.org/p/adb/adbwps/227.html

Appiah, E. N. \& McMahon, W. (2002). The Social Outcomes of Education and Feedbacks on Growth in Africa. Journal of Development Studies, 38(4), 27-68, doi: https://doi.org/10.1080/00220380412331322411

Arellano, M. \& Bond, S. (1991). Some Tests of Specification for Panel Data: Monte Carlo Evidence and an Application to Employment Equations. The Review of Economic Studies, 58(2), 277-297, doi: https://doi.org/10.2307/2297968

Artadi, E. V. \& Sala-i-Martin, X. (2003). The economic tragedy of the XXth century: growth in Africa (No. w9865). National Bureau of Economic Research. www.nber.org/papers/w9865

Bai, J. (2009). Panel Data Models with Interactive Fixed Effects. Econometrica, 77(4), 1229-1279.

Barro, R. \& Jong-Wha L. (2013). A New Data Set of Educational Attainment in the World, 1950-2010. Journal of Development Economics, 104, 184-198, doi: 10.1016/j.jdeveco.2012.10.001.

Bloom, D. E., Canning, D., Chan, K. J. \& Luca, D. L. (2014). Higher Education and Economic Growth in Africa. International Journal of African Higher Education, 1(1), 22-57, doi: https://doi.org/10.6017/ijahe.v1i1.5643.

Chi, W. (2008). The Role of Human Capital in China's Economic Development: Review and New Evidence. China Economic Review, 19(3), 421-436. 
Feenstra, R. C., Robert, I. \& Marcel, P. T. (2015). The Next Generation of the Penn World Table. American Economic Review, 105(10), 3150-3182, doi: 10.1257/aer.20130954.

Gemmell, N. (1996). Evaluating the Impacts of Human Capital Stock and Accumulation on Economic Growth: Some New Evidence. Oxford Bulletin of Economics and Statistics, 58, 9-28.

Glewwe, P., Maiga, E. \& Zheng, H. (2014). The Contribution of Education to Economic Growth: A Review of the Evidence, with Special Attention and an Application to Sub-Saharan Africa. World Development, 59, 379-393,doi: https://doi.org/10.1016/j.worlddev.2014.01.021

Gyimah-Brempong, K., Paddison, O. \& Mitiku, W. (2006). Higher Education and Economic Growth in Africa. The Journal of Development Studies, 42(3), 509-529.https://doi.org/10.1080/00220380600576490

Hausman, J. A. (1978). Specification Tests in Econometrics. Econometrica: Journal of the Econometric Society, 3, 1251-1271.

Holland, D., Liadze, I., Rienzo, C. \& Wilkinson, D. (2013). The relationship between graduates and economic growth across countries. BIS Research Paper, 110.

Jones, C. I. (1996). Human Capital, Ideas, and Economic Growth, Mimeo, Stanford: Stanford University.

Krueger, A. B. \& Lindahl, M. (2000). Education for growth: Why and for Whom? National Bureau of Economic Research.

Lucas, R. E. (1988). On the Mechanics of Economic Development. Journal of Monetary Economics, 22(1), 3-42, https://doi.org/10.1016/0304-3932(88)90168-7

Lin, T. (2006). Alternative Measure for Education Variable in an Empirical Economic Growth Model: is Primary Education Less Important? Economics Bulletin, 15, 1-6.

Mankiw, G., Romer D. \& Weil. D. (1992). A Contribution to the Empirics of Economic Growth. Quarterly Journal of Economics, 107, 407-437.

McMahon, W. (1998). Education and Growth in East Asia. Economics of Education Review, 17(2), 159-172.

Nation United. (2012). Millennium Development Goal Report. We Can End Poverty in 2050. https://doi.org/10.18356/20fbb5a4-en

Nelson, R. R. \& Phelps, E. S. (1966). Investment in Humans, Technological Diffusion, and Economic Growth. The American economic review, 56(1/2), 69-75. http://www.jstor.org/stable/1821269

Olamosu, B. \& Andy, W. (2015). Africa rising? The Economic History of Sub-Saharan Africa, from http://isj.org.uk/africa-rising/

Pegkas, P. (2014). The Link between Educational Levels and Economic Growth: A Neoclassical Approach for the Case of Greece. International Journal of Applied Economics, 11(2), 38-54.

Petrakis, P. E. \& Stamatakis, D. (2002). Growth and Educational Levels: a Comparative Analysis. Economics of Education Review, 21(5), 513-521.

Romer, P. (1990). Endogenous Technological Change. Journal of Political Economy, 98, 71-102.

Roodman, D. (2009). A Note on the Theme of Too Many Instruments. Oxford Bulletin of Economics and Statistics, 71(1), 135-158.

Shaihani, M., Harisb, A., Ismaila, N. \& Saida, R. (2011).Long Run and Short Run Effects on Education Levels: Case in Malaysia. International Journal of Economic Research, 2(6) 77-87.

Solow, R. M. (1956). A contribution to the theory of economic growth. The quarterly journal of economics, 70(1), 65-94. faculty.smu.edu/tosang/pdf/Solow_1956.pdf

Tallman, E. \& Wang. P. (1994). Human Capital and Endogenous Growth: Evidence from Taiwan. Journal of Monetary Economics, 34, 101-124.

Tang, Q., Nasiopoulos, P. \& Ward, R. K. (2008). Compensation of Requantization and Interpolation Errors in MPEG-2 to H. 264 Transcoding. IEEE Transactions on Circuits and Systems for Video Technology, 18(3). 314-325, 10.1109/TCSVT.2008.918443.

Villa, S. (2005). Determinants of Growth in Italy. A Time Series Analysis, Working Paper, University of Foggia, Italy.

Voon, J. P. (2001). Measuring Social Returns to Higher Education Investment in Hong Kong: Production Function Approach. Economics of Education Review, 20(5), 503-10, https://doi.org/10.1016/s02727757(00)00021-2.

World Fact Book. (2017). American Central Intelligent Agency. 